\title{
Comparison of Range of Motion and Strength of Hip Muscles in Female Athletes with and without Dynamic Knee Valgus
}

\section{Farzaneh Saki $^{1, *}$ (iD) Farzaneh Ramezani $^{2}$}

${ }^{I}$ Assistant Professor, Department of Sport Injury and Corrective Exercises, School of Sport Sciences, Bu-Ali Sina University, Hamadan, Iran

${ }^{2}$ MSc in Sport Injury and Corrective Exercises, Bu-Ali Sina University, Hamadan, Iran

* Corresponding Author: Farzaneh Saki, Department of Sport Injury and Corrective Exercises, School of Sport Sciences, BuAli Sina University, Hamadan, Iran. Email: f_saki@basu.ac.ir

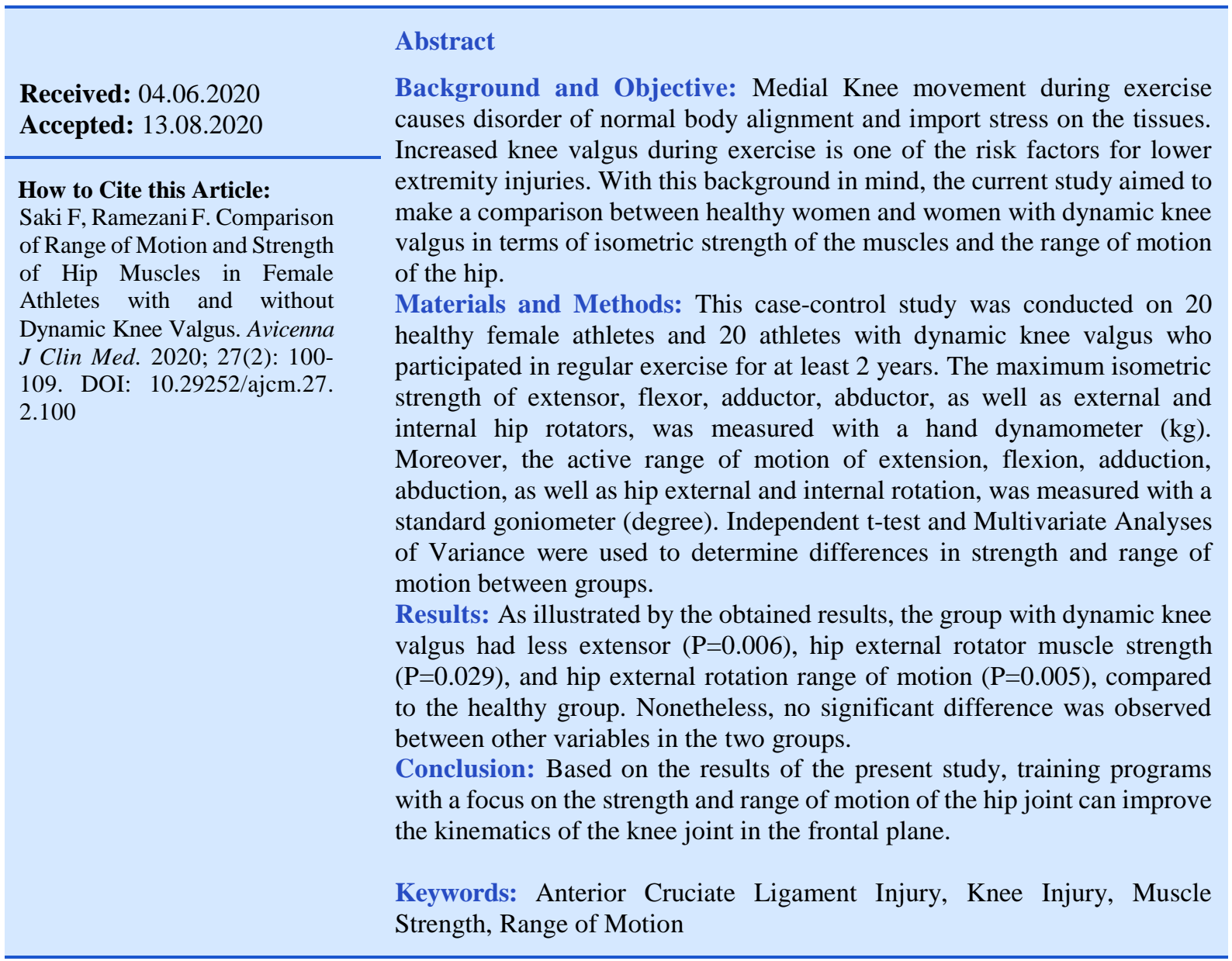




\title{
مقايسه دامنه حر كتى و قدرت عضلات هيڤ در زنان ورزشكار داراى والكوس دايناميك

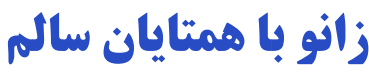

\author{
فرزانه ساكى اי* iD ، فرزانه رمضانى

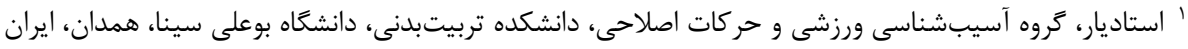

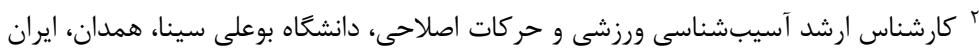 \\ * نويسنده مسئول: فرزانه ساكى، كروه آسيبشناسى ورزشى و حر كات اصلاحى، دانشكده تربيتبدنى، دانشكاه بوعلى سينا، همدان، ايران.
}

ايميل: f_saki@basu.ac.ir

\begin{tabular}{|c|c|}
\hline 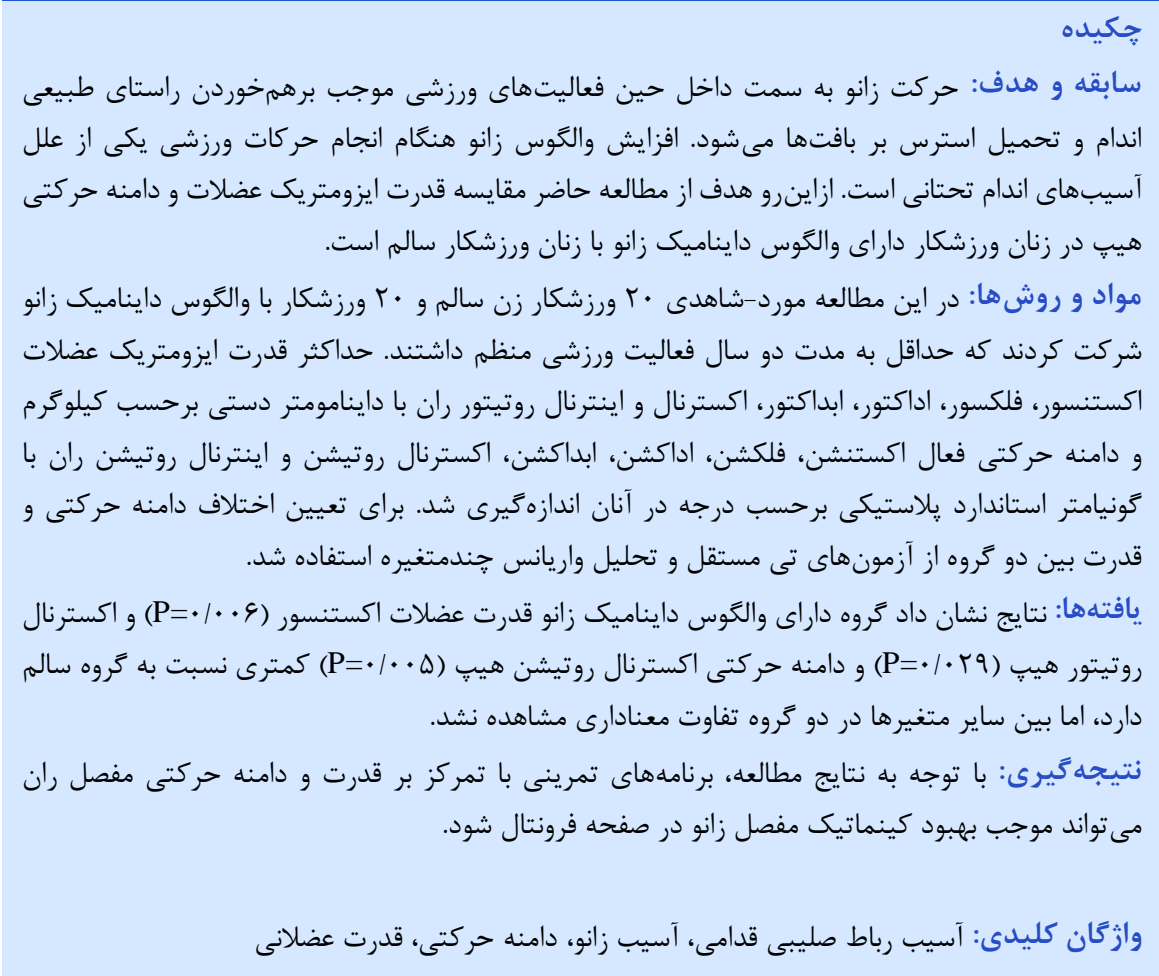 & 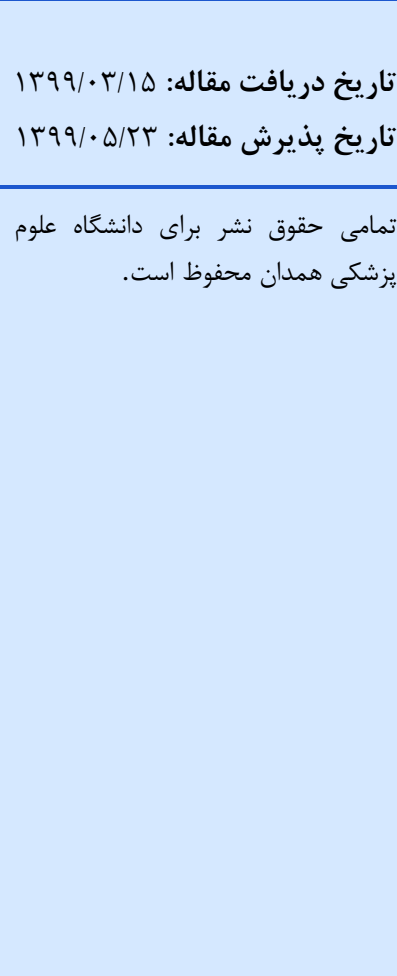 \\
\hline
\end{tabular}

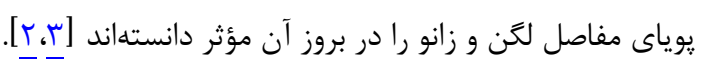

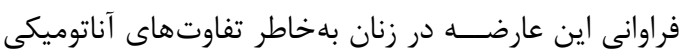

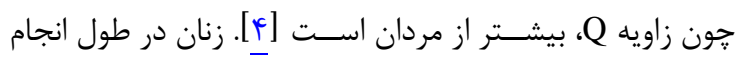

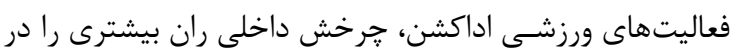

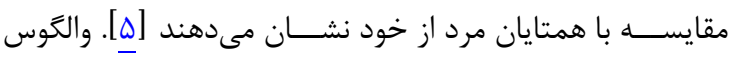

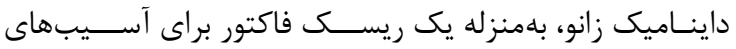

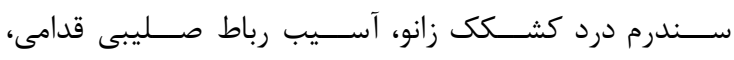

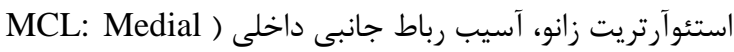
Collateral Ligament

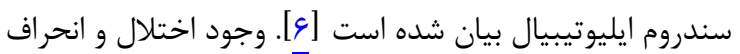

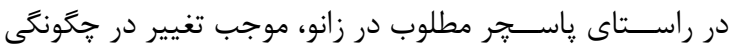

والكَوس داينـاميـك زانو بــهنونوان مجموعـهـاى از تغييرات

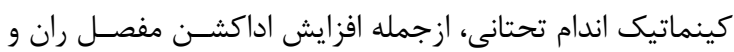

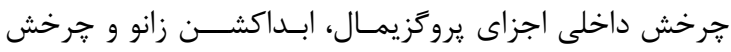

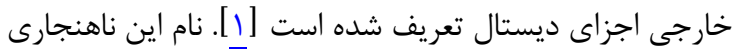

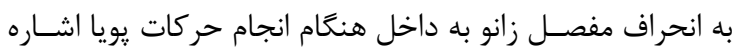

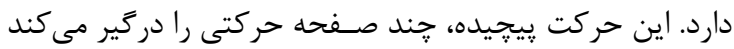
و به آسيب رباط صليبى قدامى ( ACL: Anterior Cruciate

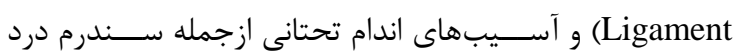
كشـكس زانو (PFPS: PatelloFemoral Pain Syndrome) منجر مىشـود. اكر جه علت دقيق اين عارضــهـ همجنان نامعلوم

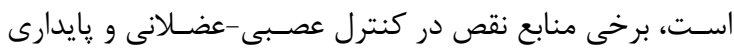




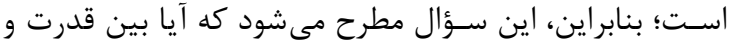

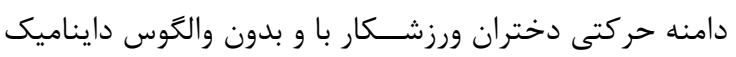
زانو تفاوتى وجود دارد.

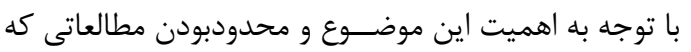

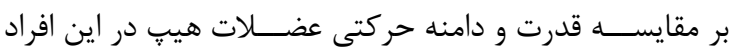

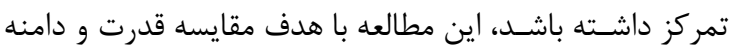

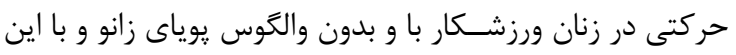

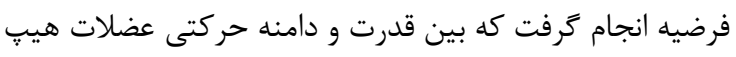

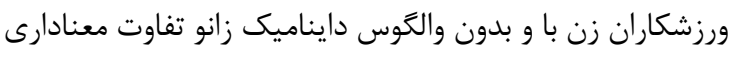

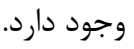

\section{مواد و روشها}

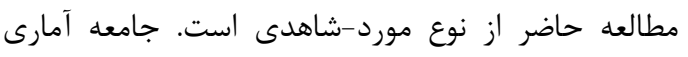

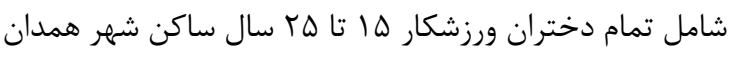

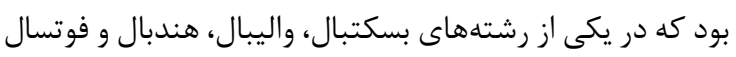

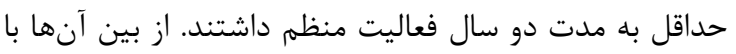

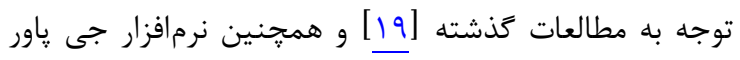

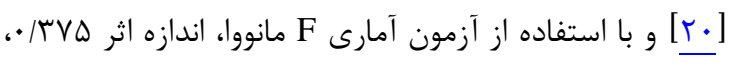

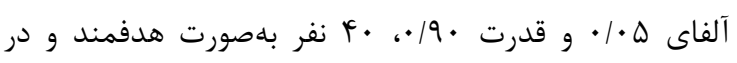

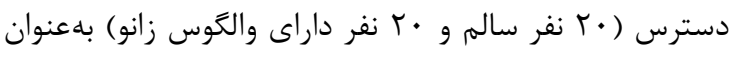

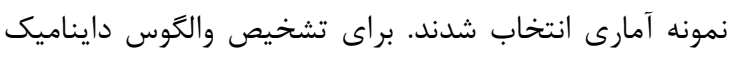

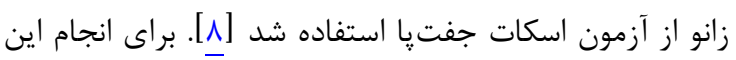

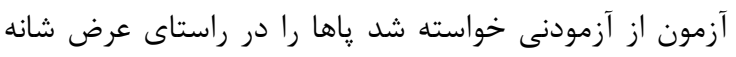

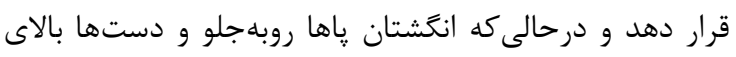

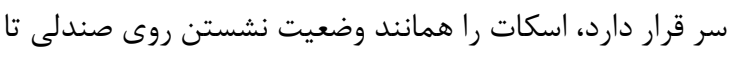

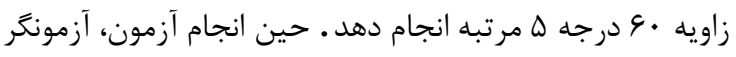

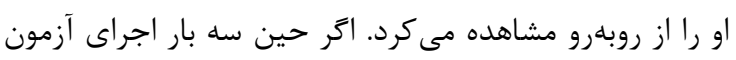

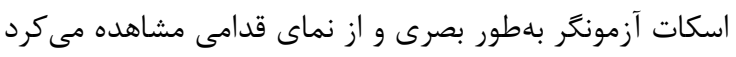

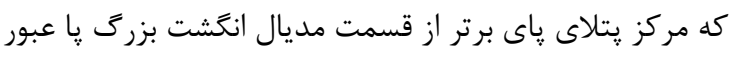

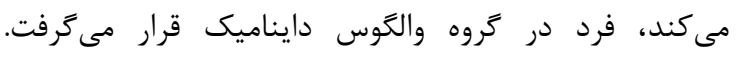

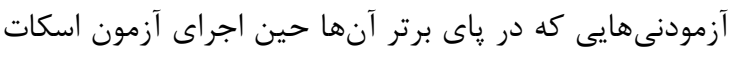

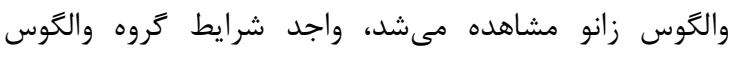

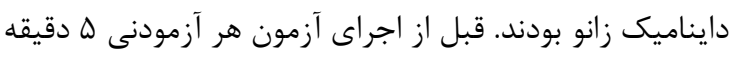
زمان براى كرمكردن در اختيار داشت.

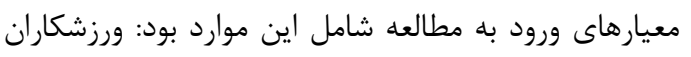

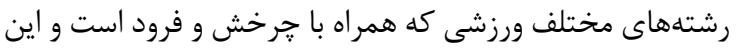

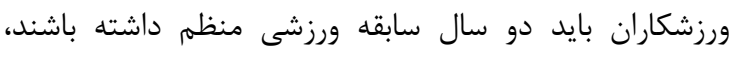

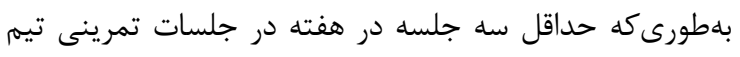

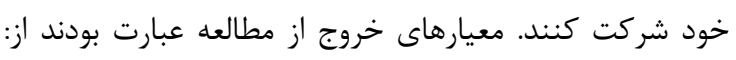

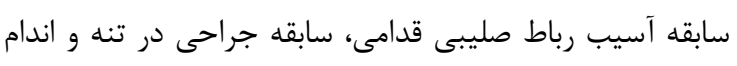

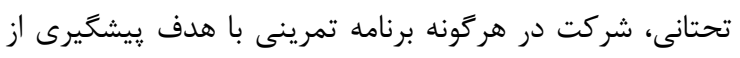

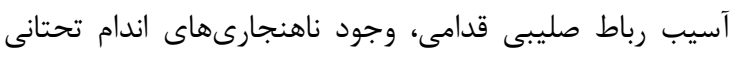

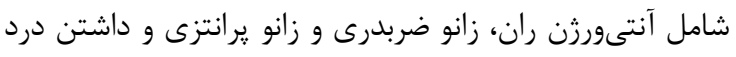

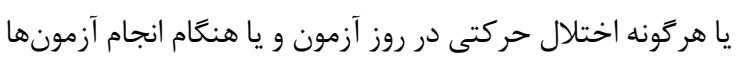

توزيع وزن بر ســاختارهاى ناحيه زانو مىشـــود. درنتيجه باعث

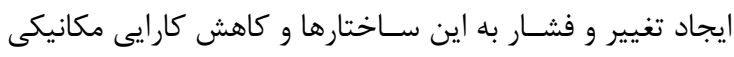

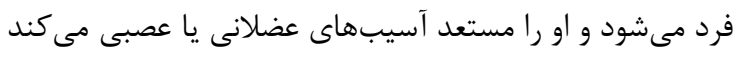

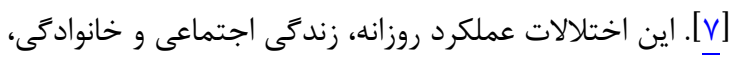

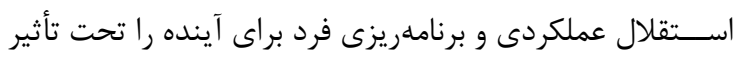

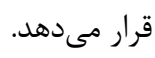

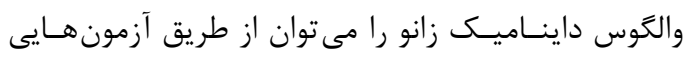

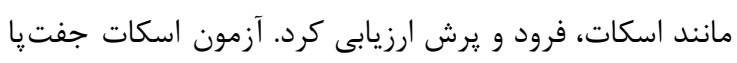

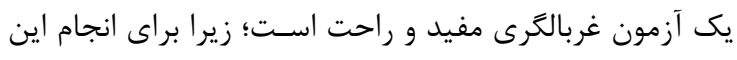

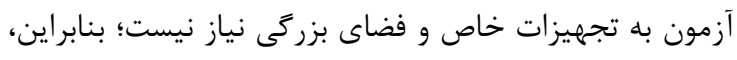

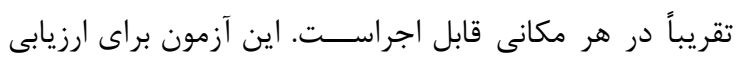

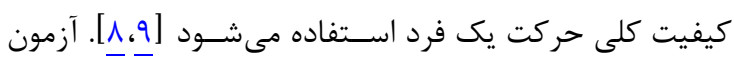

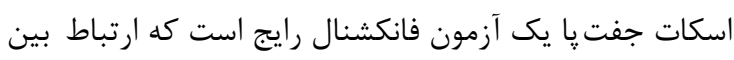

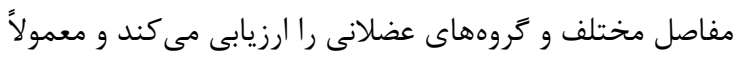

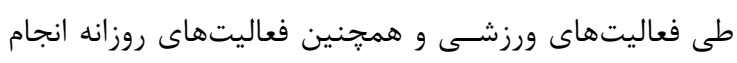

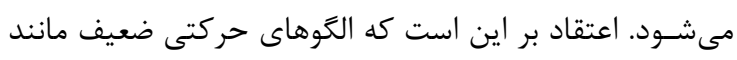

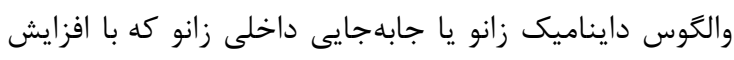

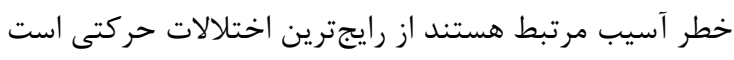

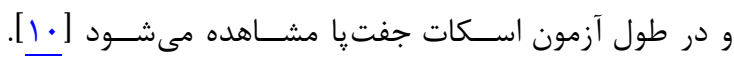

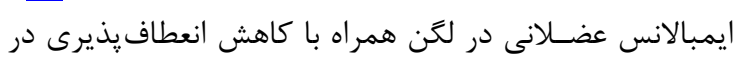

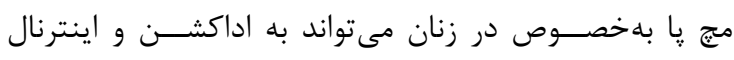

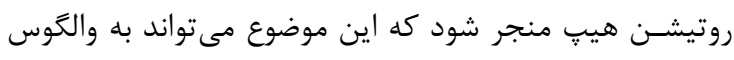

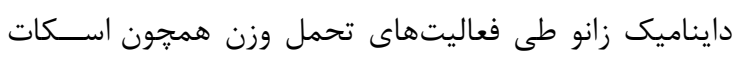

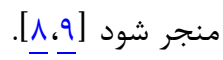

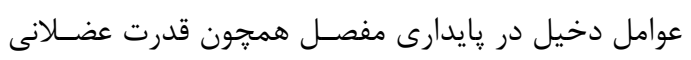

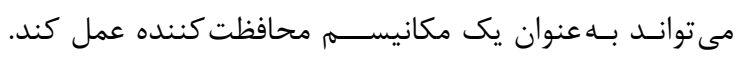

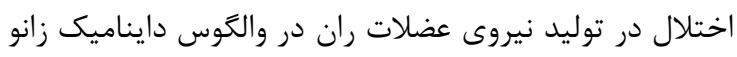

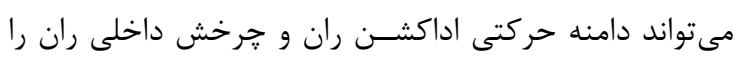

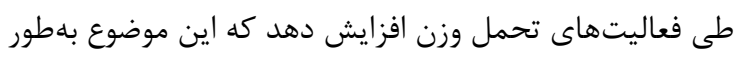

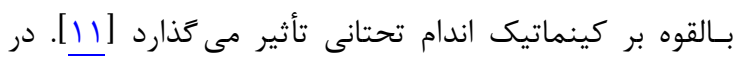

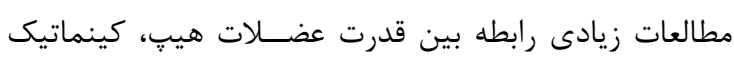

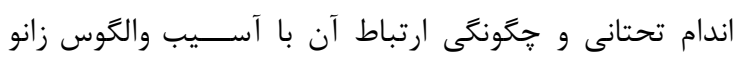

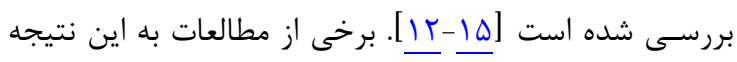

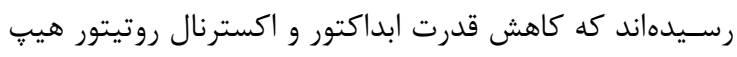

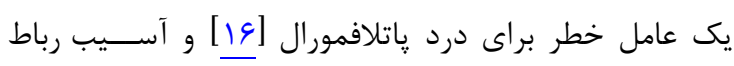

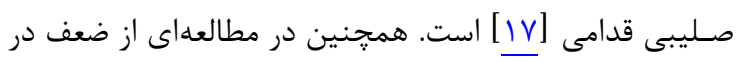

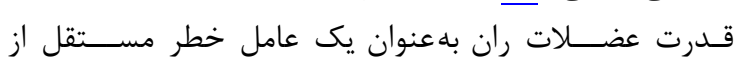

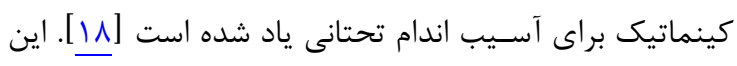

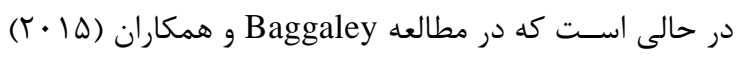

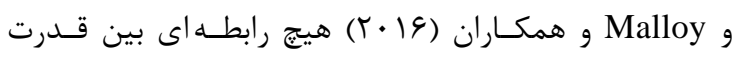

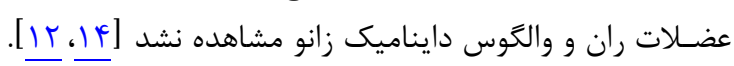

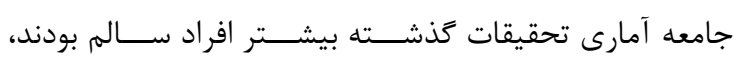

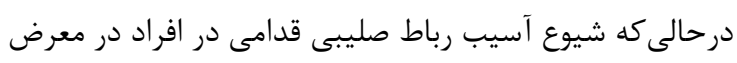

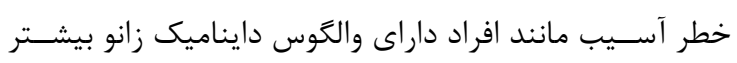


وضعيت نشسته بلهحوى كه ران و زانو فلكشن •9 درجه داشتند، لبه ميز درمان قرار كرفت. براى ارزيابى قدئ قدرت

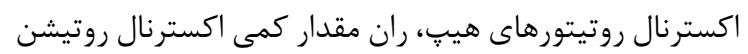
و قوزك داخلى در امتداد خط وسط بدن قرار داشت. آزمونكر رئر

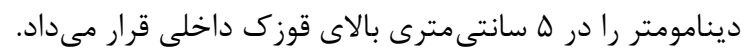

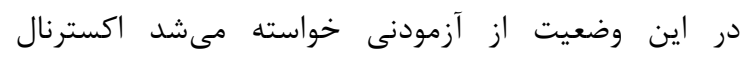

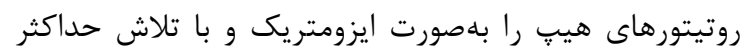

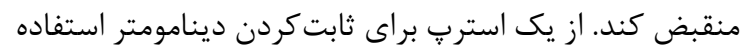

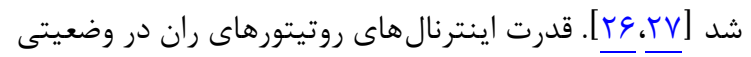

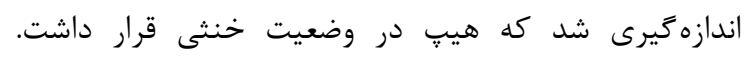

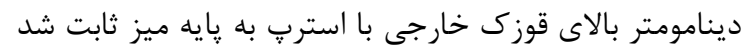

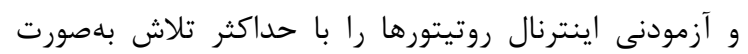
ايزومتريك منقبض مى كرد.

\section{آزمونهاى د/منه حركتى}

بامنظور ارزيابى متغيرهاى دامنه حركتى مفصل ران ران شامل دامنه حركتى فلكشن، اكستنشن، ابداكشن، اداكشن، اينترنال

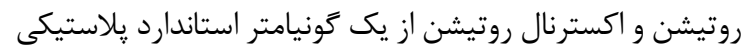

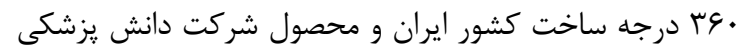

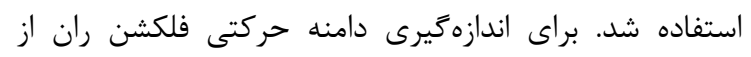
آزمودنى خواسته مىشد بهصورت طاق باز دراز بكشد. زانو و ران

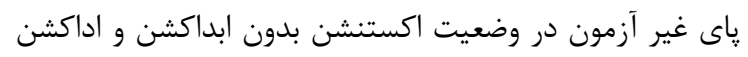

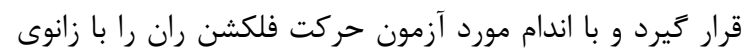

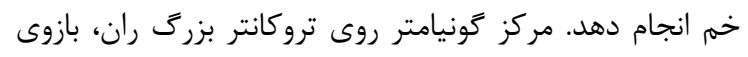

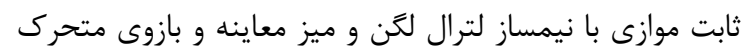

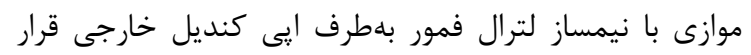
مى مرفت [rی] براى اندازهيرى دامنه حركتى اكستنشن ران از از آزمودنى

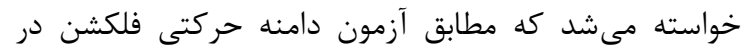

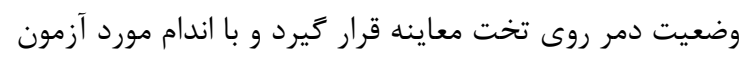

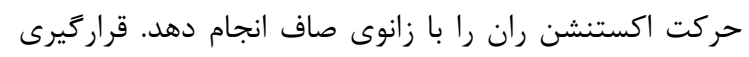

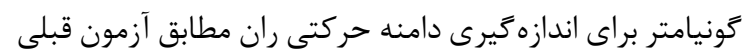

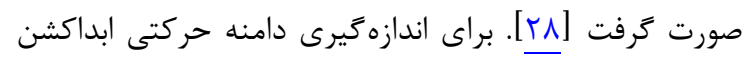

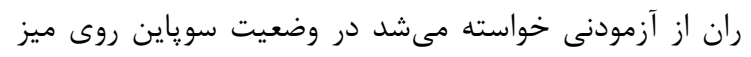

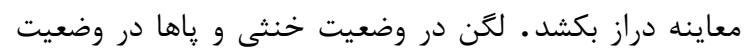

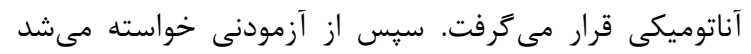

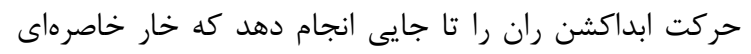

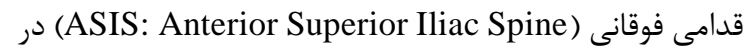
سمت مقابل به يايين حركت نكند. مركز گَونيامتر روى خار

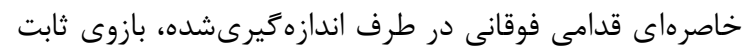

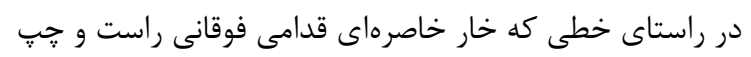

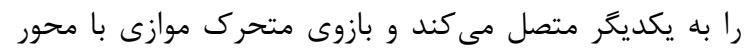

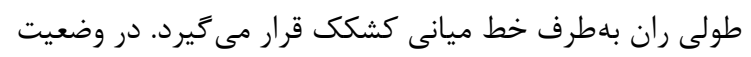

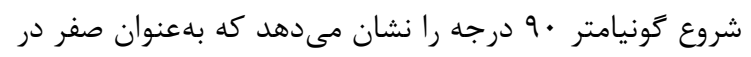

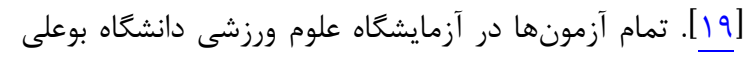

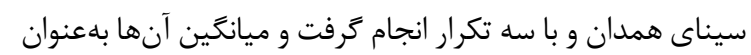

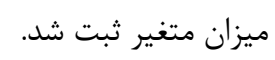

\section{آزمونهاى قدرت}

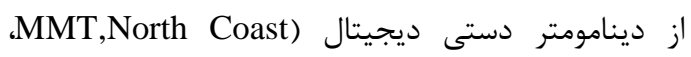

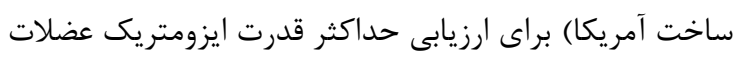

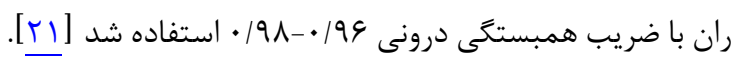

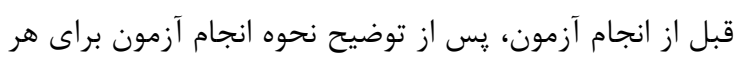

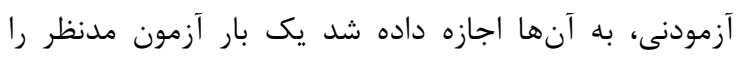

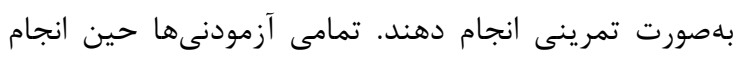

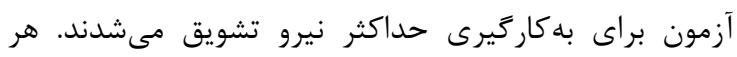

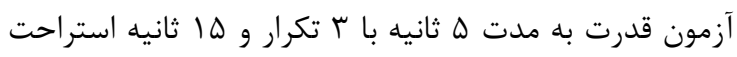

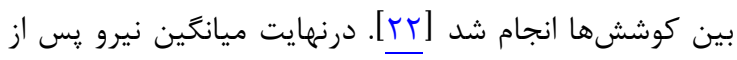

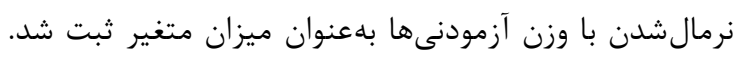

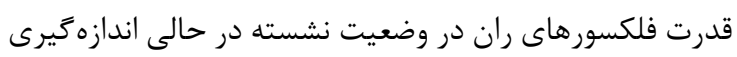

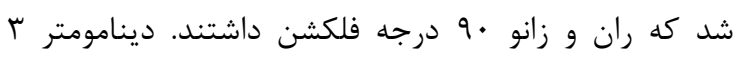

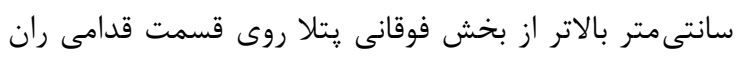
قرار داده شد. براى ثابت كردن دينامومتر از يك استر

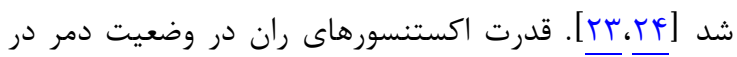

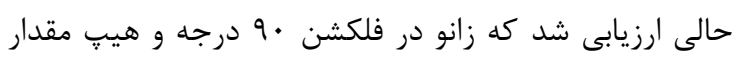

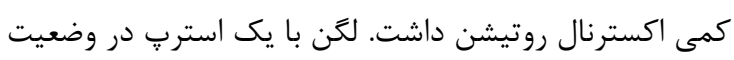

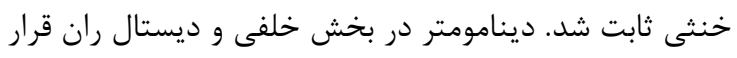

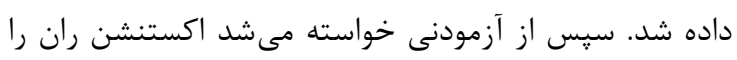

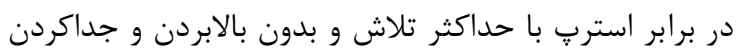

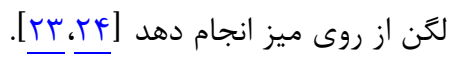

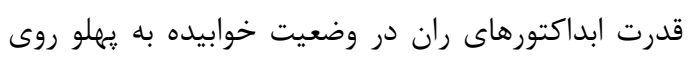

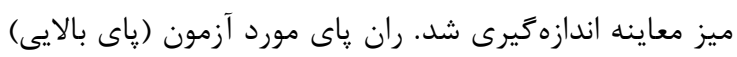

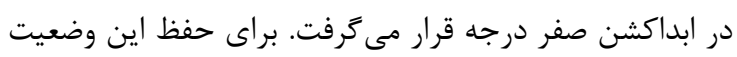

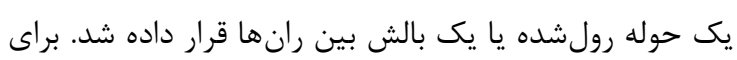

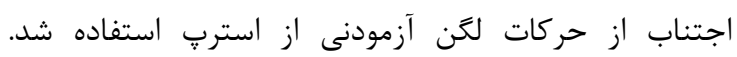

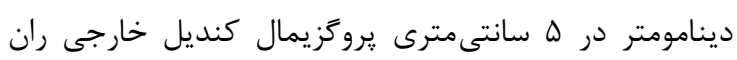

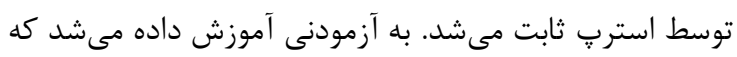

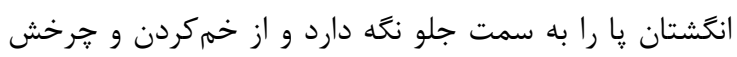

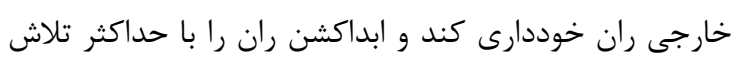

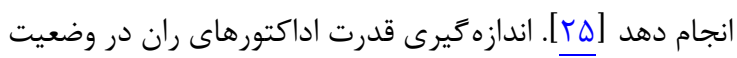

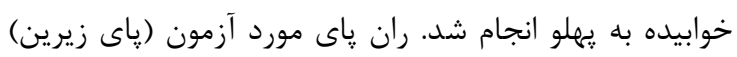

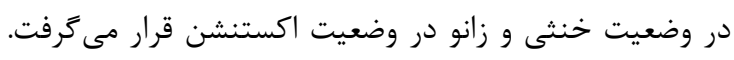

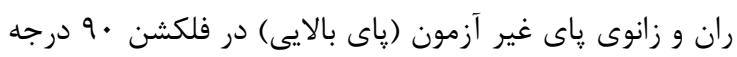

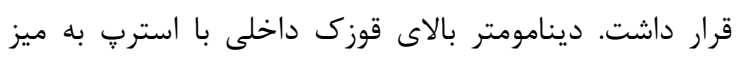

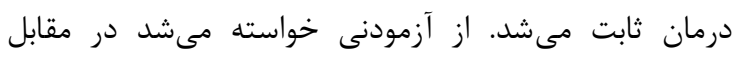

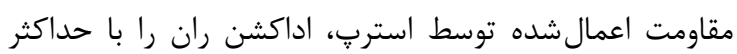
تلاش انجام دهد [هاو، سب]. براى اندازهيرى قدرت روتيتورهاى ران آنآ آزمودنى در 
از آزمون تحليل واريانس جندمتغيره استفاده شد. تحليل دادهها

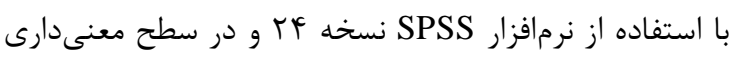

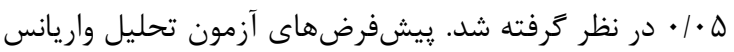

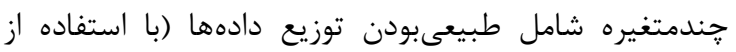
آزمون شاييرو-ويلك)، همخنى واريانس ها (با استفاده از آزمون

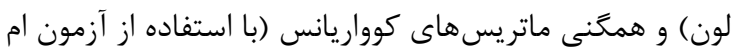
باكس) برقرار بود.

\section{يافته ها}

نتايج مطالعه حاضر نشان داد بين ويزگگىهاى دموكرافيك دو

گروه مطالعهشده تفاوت معنادارى وجود ندارد (جدول (1).

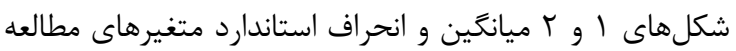

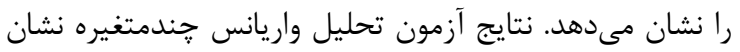
داد قدرت عضلات اكستنسور و اكسترنال روتيتورهاى ران و ودان دامنه

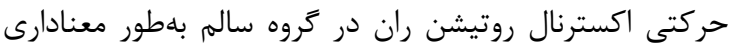

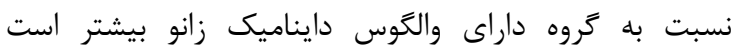

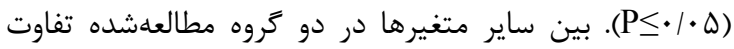

معنادارى مشاهده نشد (جدول r).
نظر كرفته شد [بر]. اندازهيرى دامنه حركتى اداكشن ران مطابق اندازهيرى

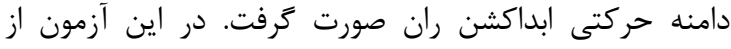

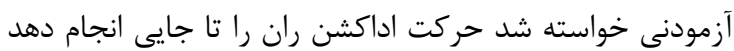

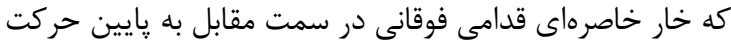

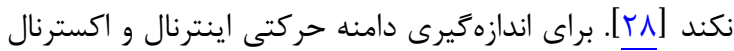

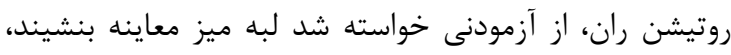

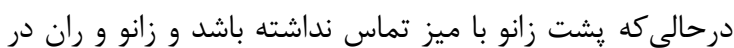

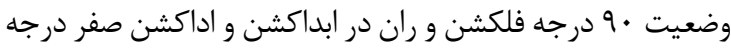

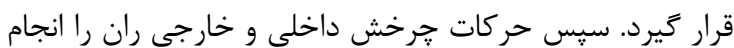

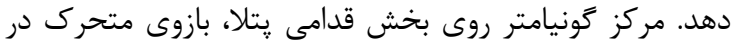

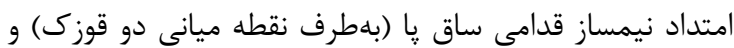

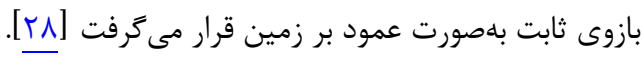

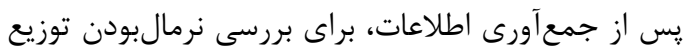

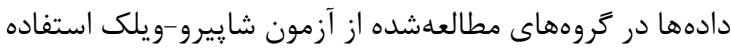

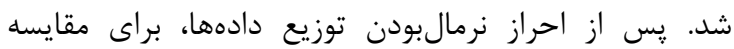

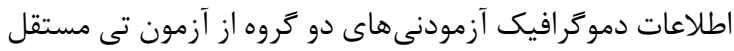
و براى مقايسه متغيرهاى تحقيق بين دو كروه سالم و والكَوس آنس

جدول ا: نتايج آزمون تى مستقل براى مقايسه ويثگى هاى دموكرافيك آزمودنىهاى دو گروه

\begin{tabular}{|c|c|c|c|c|c|c|}
\hline \multirow{2}{*}{$\mathbf{P}$} & \multirow{2}{*}{$\mathbf{t}$} & \multirow{2}{*}{ درجه } & \multirow{2}{*}{ اختلاف } & \multicolumn{2}{|c|}{ انحراف استاندارد土 ميانكين } & \\
\hline & & & & تروه والكَوس & كروه سالم & \\
\hline$\cdot / \cdot v \mathrm{~V}$ & $-1 / \wedge \mid V$ & rی & $-1 / \vee \wedge 9$ & $r) / \cdot \Delta \pm r / r q$ & $19 / r \& \pm r / V 9$ & سن (سال) \\
\hline$\cdot / Q \cdot V$ & $\cdot / 9 V$ & rی &.$/ 9 Y F$ & $19 \Delta / r \Delta \pm F / \Delta$ & $|99 /| V \pm Y / Q \mid$ & قد (سانتى متر ) \\
\hline$\cdot 11 \cdot 9$ & $-\cdot /$ KF & rᄉ & $-.19 \Delta F$ & $\Delta V / r \Delta \pm q / q \uparrow$ & $\Delta \& / V \cdot \pm V / 9 q$ & وزن (كيلوَرم) \\
\hline$\cdot|9| 1$ & $-\cdot / 0 \cdot r$ & ऍ & $-\cdot|q| F \mid$ & $r \cdot / 99 \pm r / r \cdot$ & $r \cdot|\Delta| \pm r / \Delta \Delta$ & شاخص توده بدنى (كيلوكرم بر مترمربع) \\
\hline
\end{tabular}

$r$

ra

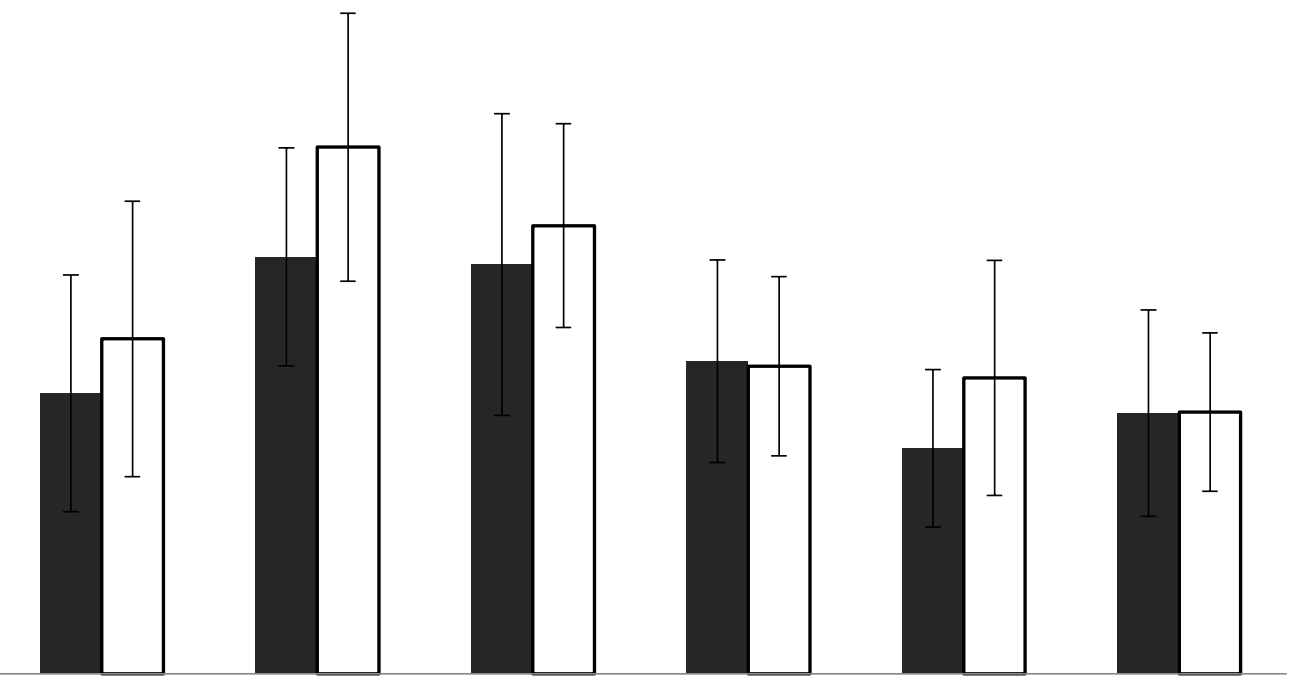

تروه والكوس

10

1.

$\omega$

قدرت اينترنال روتيشن قدرت اكسترنال قدرت اداكشن ران قدرت ابداكشن ران قدرت اكستنشن ران قدرت فلكشن ران

$$
\text { ران }
$$

شكل ا: مقايسه قدرت ورزشكاران با و بدون والكَوس دايناميك زانو (درصد وزن) 


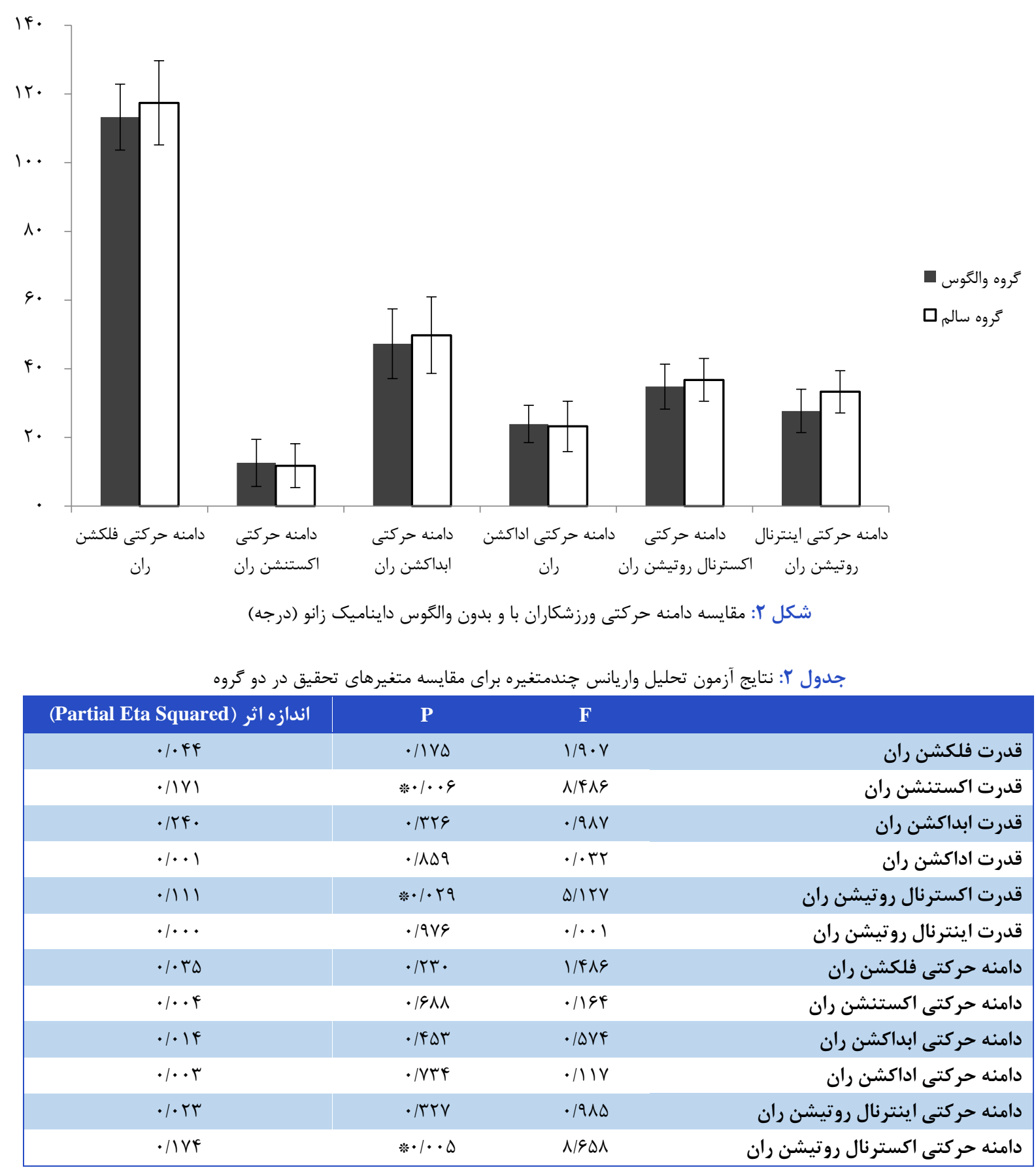

ورزشهاى يكسان در معرض آسيبهاى اندام تحتانى قرار

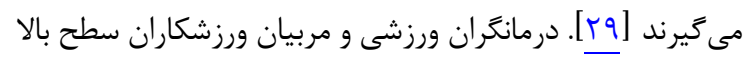
در برنامهاى اختصاصى ورزشكاران تمرينات تقويتى و كنترلى

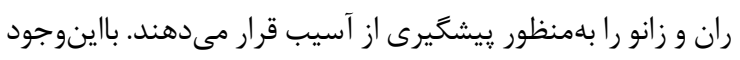

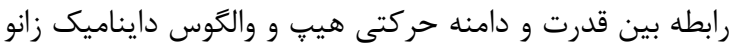

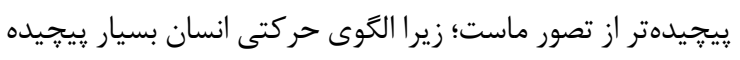

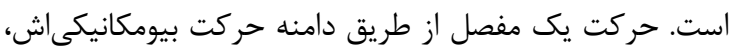

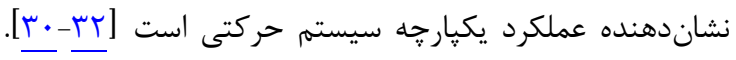

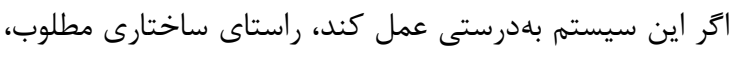

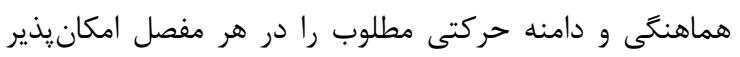

هدف اين مطالعه مقايسه قدرت و دامنه حركتى عضلات ران

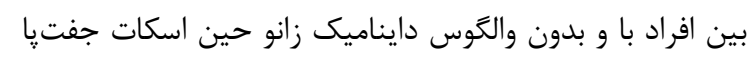

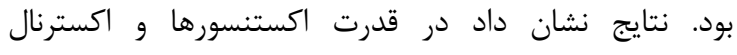

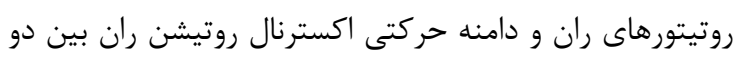

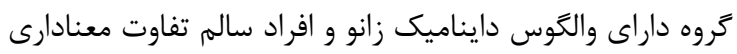

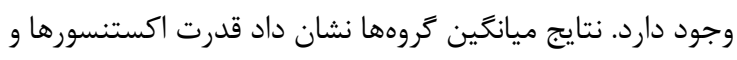

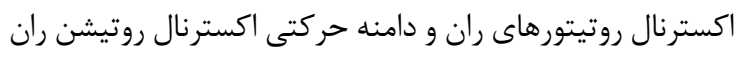

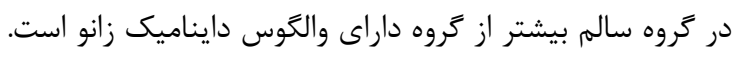

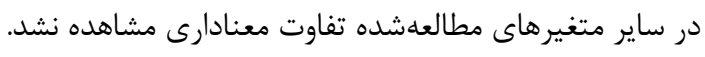

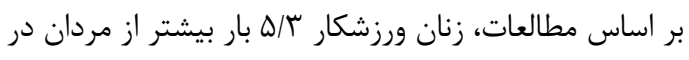


مختلف انجام شد. در اين مطالعه قبل از شروع فصل مسابقات

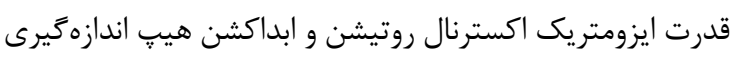

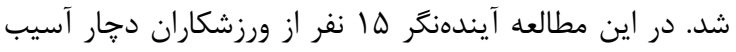

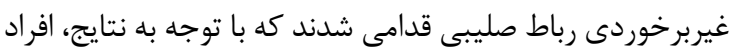

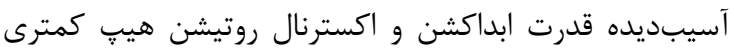

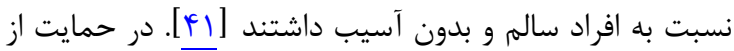
اهميت قدرت عضلات هيب، Leetun و همكاران كزارش كردند

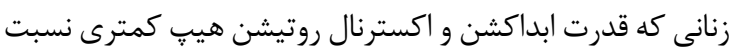

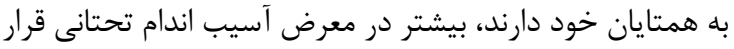

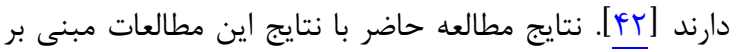

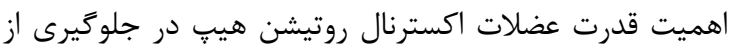

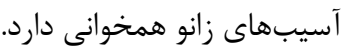

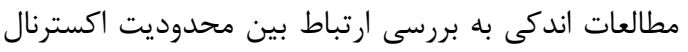
روتيشن هيب و ريسك يارگى رباط صليبى قدامى يرداختهاند.

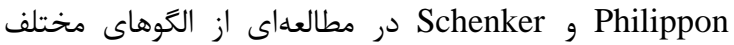

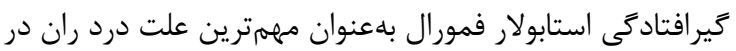

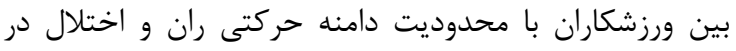

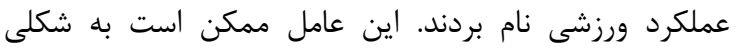

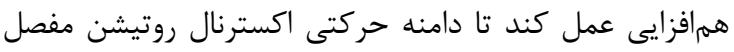

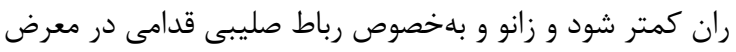

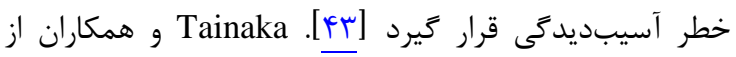

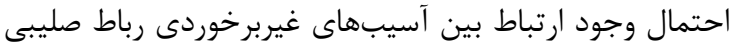

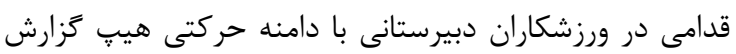

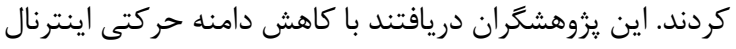

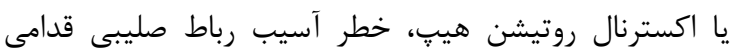

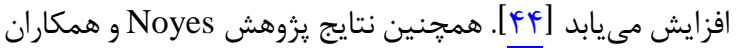

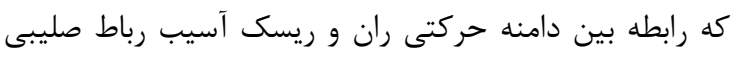

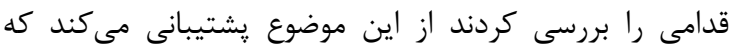

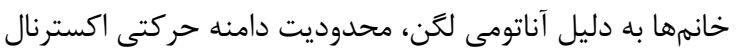

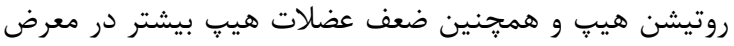

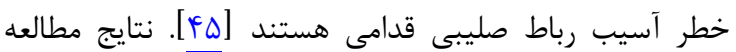
حاضر بانتايج اين مطالعات در محدوديت اكسترنال روتيشن هيب همسو است. در اين مطالعه محققان با استفاده از يك داينامومتر دستى و است

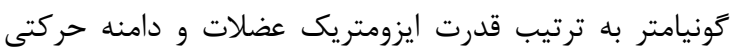

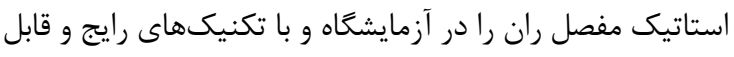

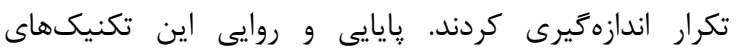

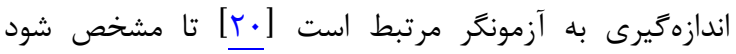

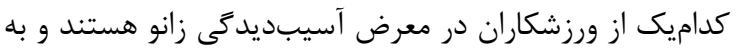

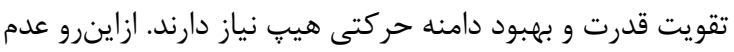
معنى دارى قدرت عضلات فلكسور، ابداكتور، اداكتور و اينترنال روتيتور و همجنين دامنه حركتى فلكشن، اكستنشن، اداكشن،

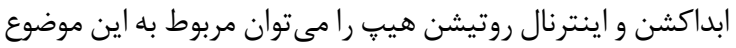

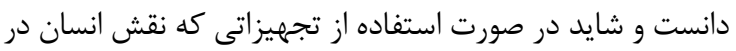

مى كند [بـ]]. اين موضوع براى طول و قدرت مناسب هر عضله و

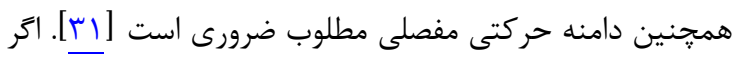
مفصلى دامنه حركتى مناسب نداشته باشد، مفصل و بافتئه

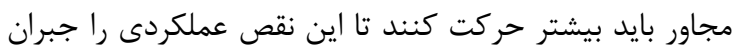

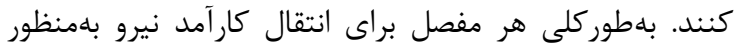

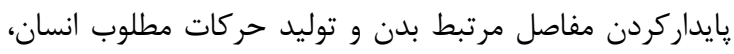

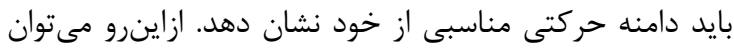

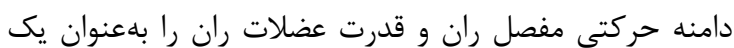
عامل تأثير تذار بر سيستم حركتى نام برد ودرد

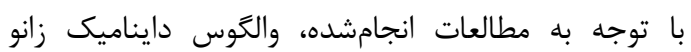
مى تواند به علت ضعف در عضلات اكستنسور، ابداكتور و اكسترنال

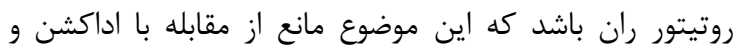

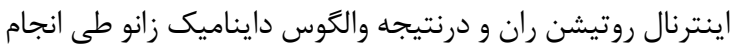

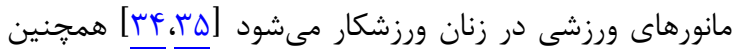

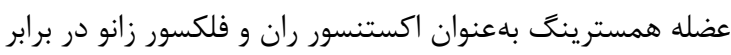

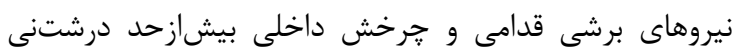

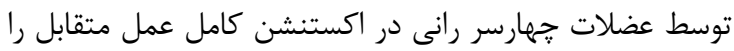

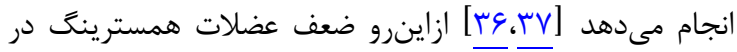
زنان ورزشكار بهعنوان يكى از عوامل آسيب رباط صليبى قدامى إنى

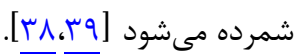
نتايج مطالعه حاضر با نتايج اين مطالعات همخوانى داشت.

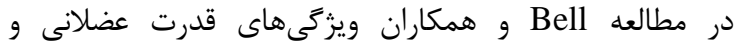

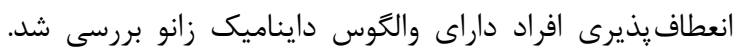

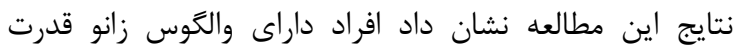

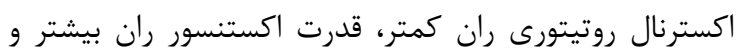

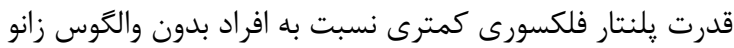

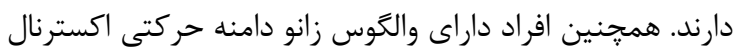

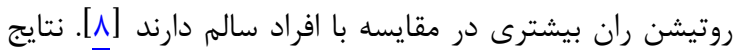
مطالعه حاضر در قدرت اكستنسورهاى ران و و داند دامنه حركتى دانى

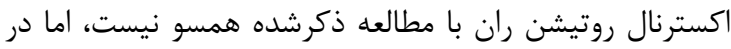

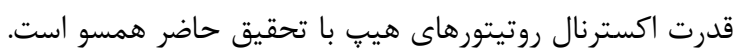

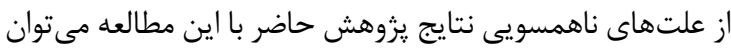

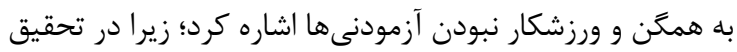

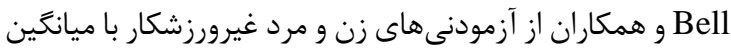

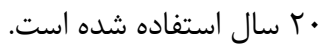

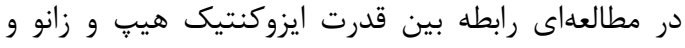

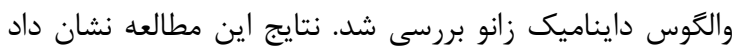

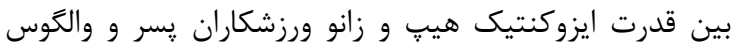
دايناميك زانو طى اسكات تكى

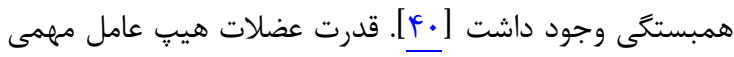

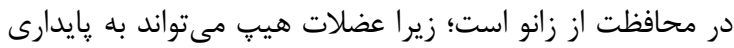

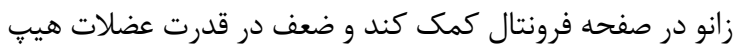

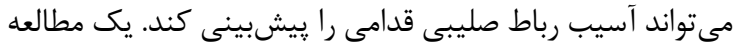

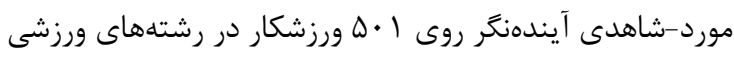


مى تواند نقش مهمى در كاهش حركت زانو در صفحه فرونتال و جلوَيرى از آسيب رباط صليبى قدامى داشته باشد.

\section{تشكر و قلروداذى مقاض}

مقاله حاضر از پايان نامه كارشناسى ارشد رشته آسيبش

ورزشى و حركات اصلاحى مصوب دانشعاه بوعلى سينا با شماره

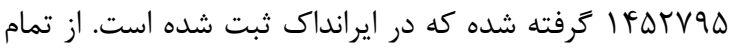
آزمودنىهايى كه در انجام اين مطالعه ما را يارى كردند و از از حمايت مالى دانشگاه كمال تشكر را داريه.

تضاد منافع بين منافع نويسندگان و نتايج مطالعه هيجزونه تعارضى

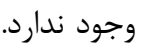

\section{ملاحظات اخلاقى}

كميته اخلاق در يزوهش دانشعاه علوم يزشكى همدان با

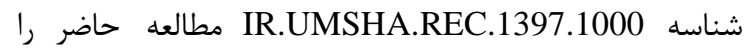

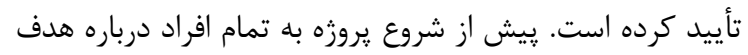

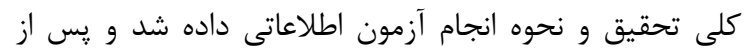

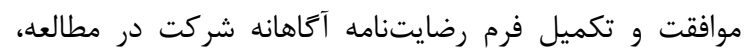
بهعنوان آزمودنى انتخاب شدند.

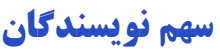

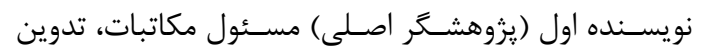

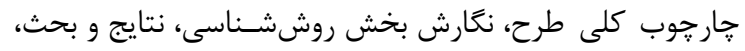

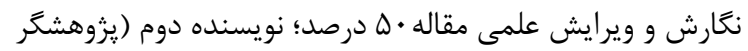

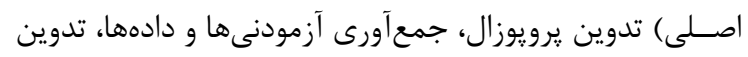
مقدمه، بازنخرى متون و مشاركت در نغارش مقاله • •ه درصد.

\section{حمايت مالذى}

دانشعاه بوعلى سينا تأمين كننده بودجه اين طرح يزوهشى
اندازهخيرى كمرنغ است مثل استفاده از دستخاه ايزوكنتيك براى قدرت و اينكلاينومتر براى دامنه حركتى، نتايج متفاوتى مشاهده مىشد.

بر اساس مطالعات والكَوس دايناميك زانو هنَّام آزمون اسكات جفتيا، متأثر از كاهش قدرت ابداكتورها و اكسترنال

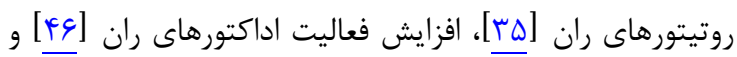

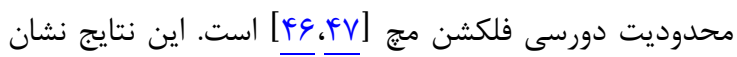
مى دهد نواقص حركتى مشاهدهده طى اسكات جفت ديا، ممكن

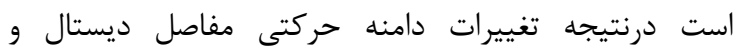

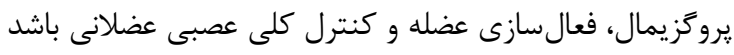

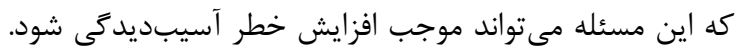

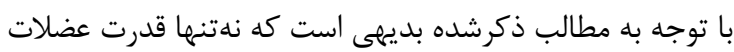

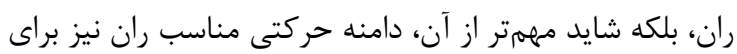

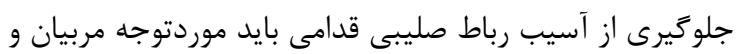

$$
\text { فيزيكال تراييستها قرار بحيرد. }
$$

مطالعه حاضر محدوديتهايى داشت؛ بلهطور مثال، از روش

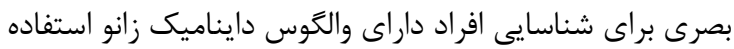

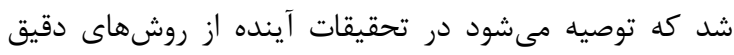

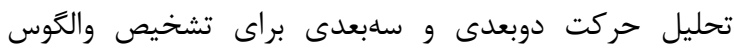

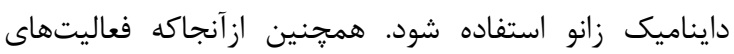
دايناميك مانند اسكات به قدرت كانسنتريك و اكسنتريك وابسته است، يِيشنهاد مىشود در مطالعات آينده ارتباط قدرت ايزوكنتيك ران و والكوس دايناميك زانو نيز بررسى شود.

\section{نتيجه تيرى}

با توجه به اينكه زنان بيشتر از مردان در معرض آسيب رباط

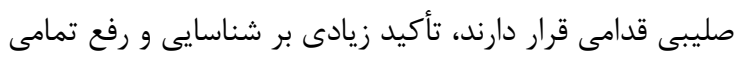

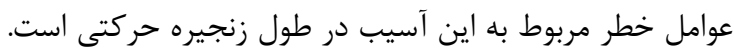

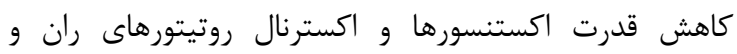
محدوديت حركتى اكسترنال روتيشن ران مى دوتواند در ايجاد

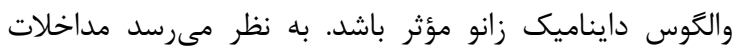

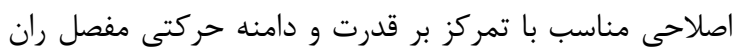

5. Mendiguchia J, Ford KR, Quatman CE, Alentorn-Geli E, Hewett TE. Sex differences in proximal control of the knee joint. Sports Med. 2011;41(7):541-57. PMID: 21688868 DOI: $10.2165 / 11589140-000000000-00000$

6. Maykut JN, Taylor-Haas JA, Paterno MV, DiCesare CA, Ford KR. Concurrent validity and reliability of $2 \mathrm{~d}$ kinematic analysis of frontal plane motion during running. Int J Sports Phys Ther. 2015;10(2):136-46. PMID: 25883862

7. Hrysomallis C, Goodman C. A review of resistance exercise and posture realignment. J Strength Cond Res. 2001; 15(3):385-90. PMID: 11710670

8. Bell DR, Padua DA, Clark MA. Muscle strength and flexibility characteristics of people displaying excessive medial knee displacement. Arch Phys Med Rehabil. 2008;89(7):1323-8. PMID: 18586134 DOI: 10.1016/j.apmr. 2007.11.048

9. Mauntel TC, Post EG, Padua DA, Bell DR. Sex differences during an overhead squat assessment. J Appl Biomech. 
2015;31(4):244-9. PMID: 25838245 DOI: 10.1123/jab.20140272

10. Post EG, Olson M, Trigsted S, Hetzel S, Bell DR. The reliability and discriminative ability of the overhead squat test for observational screening of medial knee displacement. $J$ Sport Rehabil. 2017;26(1):178. PMID: 27834577 DOI: 10.1123/jsr.2015-0178

11. Powers CM. The influence of abnormal hip mechanics on knee injury: a biomechanical perspective. J Orthop Sports Phys Ther. 2010;40(2):42-51. PMID: 20118526 DOI: $10.2519 /$ jospt.2010.3337

12. Baggaley M, Noehren B, Clasey JL, Shapiro R, Pohl MB. Frontal plane kinematics of the hip during running: are they related to hip anatomy and strength? Gait Posture. 2015;42(4):505-10. PMID: 26364243 DOI: 10.1016/j. gaitpost.2015.07.064

13. Nilstad A, Krosshaug T, Mok KM, Bahr R, Andersen TE. Association between anatomical characteristics, knee laxity, muscle strength, and peak knee valgus during vertical dropjump landings. J Orthop Sports Phys Ther. 2015;45(12):9981005. PMID: 26381485 DOI: 10.2519/jospt.2015.5612

14. Malloy P, Morgan A, Meinerz C, Geiser CF, Kipp K. Hip external rotator strength is associated with better dynamic control of the lower extremity during landing tasks. $J$ Strength Cond Res. 2016;30(1):282-91. PMID: 26110347 DOI: 10.1519/JSC.0000000000001069

15. Hollman JH, Galardi CM, Lin IH, Voth BC, Whitmarsh CL. Frontal and transverse plane hip kinematics and gluteus maximus recruitment correlate with frontal plane knee kinematics during single-leg squat tests in women. Clin Biomech. 2014;29(4):468-74. PMID: 24467971 DOI: 10.1016/j.clinbiomech.2013.12.017

16. Chumanov ES, Wall-Scheffler C, Heiderscheit BC. Gender differences in walking and running on level and inclined surfaces. Clin Biomech. 2008;23(10):1260-8. PMID: 18774631 DOI: 10.1016/j.clinbiomech.2008.07.011

17. Ramskov D, Barton C, Nielsen RO, Rasmussen S. High eccentric hip abduction strength reduces the risk of developing patellofemoral pain among novice runners initiating a self-structured running program: a 1-year observational study. J Orthop Sports Phys Ther. 2015; 45(3):153-61. PMID: 25627149 DOI: 10.2519/jospt. 2015.5091

18. Rathleff M, Rathleff C, Crossley K, Barton C. Is hip strength a risk factor for patellofemoral pain? A systematic review and meta-analysis. Br J Sports Med. 2014;48(14):1088. DOI: 10.1136/bjsports-2013-093305

19. Saki F, Rajabi R, Tabatabaei F. Relationship between hip and knee strength and knee valgus angle during drop jump in elite female athletes. Phys Treat Specific Phys Ther J. 2014; 4(1):39-46.

20. Lawrence RK 3rd, Kernozek TW, Miller EJ, Torry MR, Reuteman P. Influences of hip external rotation strength on knee mechanics during single-leg drop landings in females. Clin Biomech. 2008;23(6):806-13. PMID: 18395310 DOI: 10.1016/j.clinbiomech.2008.02.009

21. Jackson SM, Cheng MS, Smith Jr AR, Kolber MJ. Intrarater reliability of hand held dynamometry in measuring lower extremity isometric strength using a portable stabilization device. Musculoskelet Sci Pract. 2017;27:137-41. PMID: 27476066 DOI: $10.1016 /$ j.math.2016.07.010

22. Willson JD, Davis IS. Lower extremity strength and mechanics during jumping in women with patellofemoral pain. J Sport Rehabil. 2009;18(1):76-90. PMID: 19321908 DOI: $10.1123 /$ jsr.18.1.76

23. Magalhães E, Fukuda TY, Sacramento SN, Forgas A, Cohen M, Abdalla RJ. A comparison of hip strength between sedentary females with and without patellofemoral pain syndrome. J Orthop Sports Phys Ther. 2010;40(10):641-7. PMID: 20508327 DOI: 10.2519/jospt.2010.3120

24. Cichanowski HR, Schmitt JS, Johnson RJ, Niemuth PE. Hip strength in collegiate female athletes with patellofemoral pain. Med Sci Sports Exerc. 2007;39(8):1227-32. PMID: 17762354 DOI: $10.1249 / \mathrm{mss} .0 \mathrm{~b} 013 \mathrm{e} 3180601109$

25. Krause DA, Schlagel SJ, Stember BM, Zoetewey JE, Hollman JH. Influence of lever arm and stabilization on measures of hip abduction and adduction torque obtained by hand-held dynamometry. Arch Phys Med Rehabil. 2007; 88(1):37-42. PMID: 17207673 DOI: 10.1016/j.apmr. $\underline{2006.09 .011}$

26. Robinson RL, Nee RJ. Analysis of hip strength in females seeking physical therapy treatment for unilateral patellofemoral pain syndrome. J Orthop Sports Phys Ther. 2007;37(5):232-8. PMID: 17549951 DOI: $10.2519 /$ jospt.2007.2439

27. Dierks TA, Manal KT, Hamill J, Davis IS. Proximal and distal influences on hip and knee kinematics in runners with patellofemoral pain during a prolonged run. J Orthop Sports Phys Ther. 2008;38(8):448-56. PMID: 18678957 DOI: 10.2519/jospt.2008.2490

28. Clark M, Lucett S. NASM essentials of corrective exercise training. Philadelphia: Lippincott Williams \& Wilkins; 2010.

29. Krosshaug T, Nakamae A, Boden BP, Engebretsen L, Smith $\mathrm{G}$, Slauterbeck JR, et al. Mechanisms of anterior cruciate ligament injury in basketball: video analysis of 39 cases. Am J Sports Med. 2007;35(3):359-67. PMID: 17092928 DOI: $10.1177 / 0363546506293899$

30. Comerford MJ, Mottram SL. Movement and stability dysfunction-contemporary developments. Man Ther. 2001; 6(1):15-26. PMID: 11243905 DOI: $10.1054 /$ math.2000.0388

31. Sahrmann S. Diagnosis and treatment of movement impairment syndromes. St. Louis: Mosby; 2002.

32. Liebenson C. Integrating rehabilitation into chiropractic practice (blending active and passive care). Rehabilitation of the Spine. Baltimore: Williams \& Wilkins; 1996. P. 13-43.

33. Panjabi MM. The stabilizing system of the spine. Part I. Function, dysfunction, adaptation, and enhancement. J Spinal Disord. 1992;5(4):383-9. PMID: 1490034 DOI: 10.1097/ 00002517-199212000-00001

34. Dix J, Marsh S, Dingenen B, Malliaras P. The relationship between hip muscle strength and dynamic knee valgus in asymptomatic females: a systematic review. Phys Ther Sport. 2019;37:197-209. PMID: 29859898 DOI: 10.1016/j.ptsp. 2018.05.015

35. Ireland ML, Willson JD, Ballantyne BT, Davis IM. Hip strength in females with and without patellofemoral pain. $J$ Orthop Sports Phys Ther. 2003;33(11):671-6.

36. Aagaard P, Simonsen E, Andersen J, Magnusson S, BojsenMøller F, Dyhre-Poulsen P. Antagonist muscle coactivation during isokinetic knee extension. Scand J Med Sci Sports. 2000;10(2):58-67. PMID: 10755275 DOI: 10.1034/j.16000838.2000.010002058.x

37. Blackburn JT, Padua DA. Influence of trunk flexion on hip and knee joint kinematics during a controlled drop landing. Clin Biomech. 2008;23(3):313-9. PMID: 18037546 DOI: 10.1016/j.clinbiomech.2007.10.003

38. Buckley B, Kaminski T. Hamstring and quadriceps strength ratios in healthy males and females: implications for ACL injury. J Athl Train. 2003;38(2):S14-5.

39. Pfeifer CE, Beattie PF, Sacko RS, Hand A. Risk factors associated with non-contact anterior cruciate ligament injury: a systematic review. Int J Sports Phys Ther. 2018;13(4):57587. PMID: 30140551

40. Mail MS, Azhar NM, Affandi NF, Shaharudin S, Agrawal S, Chee LM. Relationship between isokinetic leg strength and knee frontal plane projection angle during single leg squat among male junior athletes. $J$ Health Translat Med. 2019;22(2):43-8. DOI: 10.22452/jummec.vol22no2.7

41. Khayambashi K, Ghoddosi N, Straub RK, Powers CM. Hip muscle strength predicts noncontact anterior cruciate ligament injury in male and female athletes: a prospective study. Am J Sports Med. 2016;44(2):355-61. PMID: 26646514 DOI: $10.1177 / 0363546515616237$

42. Leetun DT, Ireland ML, Willson JD, Ballantyne BT, Davis IM. Core stability measures as risk factors for lower extremity injury in athletes. Med Sci Sports Exerc. 2004;36(6):926-34. PMID: 15179160 DOI: 10.1249/01.mss. 0000128145.75199.c3

43. Philippon MJ, Schenker ML. Arthroscopy for the treatment of femoroacetabular impingement in the athlete. Clin Sports Med. 2006;25(2):299-308. PMID: 16638493 DOI: 10.1016/j.csm.2005.12.006

44. Tainaka K, Takizawa T, Kobayashi H, Umimura M. Limited hip rotation and non-contact anterior cruciate ligament injury: a case-control study. Knee. 2014;21(1):86-90. PMID: 
23953661 DOI: 10.1016/j.knee.2013.07.006

45. Noyes FR, Barber-Westin S. ACL injuries in the female athlete: causes, impacts, and conditioning programs. Berlin, Germany: Springer; 2018.

46. Vesci B, Padua D, Bell D, Strickland L, Guskiewicz K, Hirth C. Influence of hip muscle strength, flexibility of hip and ankle musculature, and hip muscle activation on dynamic knee valgus motion during a double-legged squat. $J$ Athl Train. 2007;42(2 Suppl):83.

47. Bell D, Padua D. Influence of ankle dorsiflexion range of motion and lower leg muscle activation on medial knee displacement during a double-legged squat. J Athl Train. 2008; $\mathbf{4 3}(5): 543-5$. 